\title{
Bach 1 Deficiency and Accompanying Overexpression of Heme Oxygenase-1 Do Not Influence Aging or Tumorigenesis in Mice
}

\author{
Kazushige Ota, ${ }^{1,2}$ Andrey Brydun, ${ }^{1}$ Ari Itoh-Nakadai, ${ }^{1}$ \\ Jiying Sun, ${ }^{3}$ and Kazuhiko Igarashi ${ }^{1,4}$ \\ ${ }^{1}$ Department of Biochemistry, Tohoku University Graduate School of Medicine, 2-1 Seiryo-machi, Sendai 980-0872, Japan \\ ${ }^{2}$ Division of Nephrology, Endocrinology, and Vascular Medicine, Tohoku University Graduate School of Medicine, 2-1 Seiryo-machi, \\ Sendai 980-0872, Japan \\ ${ }^{3}$ Department of Cellular Biology, Research Institute for Radiation Biology and Medicine, Hiroshima University, \\ Hiroshima 734-8551, Japan \\ ${ }^{4}$ Center for Regulatory Epigenome and Diseases, Tohoku University Graduate School of Medicine, 2-1 Seiryo-machi, \\ Sendai 980-0872, Japan
}

Correspondence should be addressed to Kazuhiko Igarashi; igarashi@med.tohoku.ac.jp

Received 3 March 2014; Accepted 22 May 2014; Published 23 June 2014

Academic Editor: Carlos Caulin

Copyright (C) 2014 Kazushige Ota et al. This is an open access article distributed under the Creative Commons Attribution License, which permits unrestricted use, distribution, and reproduction in any medium, provided the original work is properly cited.

\begin{abstract}
Oxidative stress contributes to both aging and tumorigenesis. The transcription factor Bach1, a regulator of oxidative stress response, augments oxidative stress by repressing the expression of heme oxygenase-1 (HO-1) gene (Hmoxl) and suppresses oxidative stress-induced cellular senescence by restricting the p53 transcriptional activity. Here we investigated the lifelong effects of Bach1 deficiency on mice. Bach1-deficient mice showed longevity similar to wild-type mice. Although HO-1 was upregulated in the cells of Bach1-deficient animals, the levels of ROS in Bach1-deficient HSCs were comparable to those in wild-type cells. Bach1 $1^{-1-}$; $553^{-1-}$ mice succumbed to spontaneous cancers as frequently as $p 53$-deficient mice. Bach1 deficiency significantly altered transcriptome in the liver of the young mice, which surprisingly became similar to that of wild-type mice during the course of aging. The transcriptome adaptation to Bachl deficiency may reflect how oxidative stress response is tuned upon genetic and environmental perturbations. We concluded that Bach1 deficiency and accompanying overexpression of HO-1 did not influence aging or p53 deficiency-driven tumorigenesis. Our results suggest that it is useful to target Bachl for acute injury responses without inducing any apparent deteriorative effect.
\end{abstract}

\section{Introduction}

Elimination of excessive reactive oxygen species (ROS) is pivotal to prevent malignant transformation and to maintain tissue homeostasis [1], because they modify DNA, lipids, and proteins, compromising their functions. According to the "free radical theory," aging results from the accumulation of the cellular damage due to oxidative stress $[2,3]$. Cells are equipped with many protective genes against ROS, among which heme oxygenase-1 (HO-1) is placed in the central position in that its expression is strongly induced in response to oxidative stress and is tightly associated with the progression of diseases involving oxidative stress [4-6]. The two beneficial functions of HO- 1 have been pointed out. First, it reduces the levels of free heme, which catalyzes the production of ROS by the Fenton reaction. Second, among the products of HO1 reaction, biliverdin and carbon monoxide $(\mathrm{CO})$ mitigate ROS. Since genetic ablation of HO-1 in mice causes severe anemia, disorders of iron homeostasis, and shortening of life span, HO-1 is indispensable for organismal homeostasis [7]. Reflecting its antioxidant activities, it has been shown that the overexpression of $\mathrm{HO}-1$ is protective against diverse tissue damages in disease models of mice, including disorders of heart, liver, lung, and intestine [8-11]. However, overexpression of HO-1 has also been considered to result in a pathological iron deposition and mitochondrial damage in 
aging-related neurodegenerative diseases [12]. Thus, whether a long-term overexpression of HO-1 would be protective or induce detrimental side effects still remains to be examined.

$\mathrm{HO}-1$ is an inducible enzyme and its expression is mainly determined by the transcription level of Hmoxl gene [13-16]. The transcription factor Bachl forms heterodimers with small Maf oncoproteins and binds to the Maf-recognition elements (MARE) in the enhancer regions of Hmoxl to repress its transcription [13,17-22], whereas heterodimers composed of Nrf2 and small Maf oncoproteins bind to the same sequences to activate Hmoxl [21, 23-25]. In Bach1-deficient mice, the levels of HO-1 are higher compared with control mice in many tissues, including the liver, indicating that Bach1 is a physiological repressor of Hmox1 [18]. The protective effect of HO-1 appears to be constrained by Bach1 under several specific disease conditions, because Bach1-deficient mice are more resistant to tissue damage than wild-type mice in the models of lung, liver, intestine, and cardiovascular diseases [26-31]. Another function of the Bach1-HO-1 axis resides in the regulation of innate immunity [32]. Particularly, the Bachl-HO-1 axis is important for the proper function of the antigen presenting cells such as macrophages and dendritic cells [32].

Recently we have reported that Bachl restricts the implementation of cellular senescence transcription program in mouse embryonic fibroblasts (MEFs) [33]. Cellular senescence is induced by ROS through DNA damage responses and acts as a barrier against malignant transformation of damaged cells $[34,35]$. The tumor suppressor p53 induces cellular senescence in response to oxidative stress, oncogenic stress, and direct DNA damage [36]. Bach1 represses p53-mediated cellular senescence by forming a complex with p53, recruiting histone deacetylase-1 (HDAC1) and thereby repressing a subset of p53 target genes through histone deacetylation $[33,37]$. Bach1 specifically inhibits oxidative stress-induced p53-dependent cellular senescence [33]. The p53-Bach1 interaction is inhibited by the tumor suppressor p19 ARF [38], which is consistent with the senescence-restricting function of Bach1. Furthermore, Bach1-deficient MEFs are resistant to transformation by activated H-Ras oncogene, which is known to utilize increased levels of ROS for transformation [39]. Therefore, a reduction in the Bach1 activity may lead to an enhancement in the tumor-resistant phenotype. However, the roles of Bachl in tumorigenesis are controversial. There are several reports suggesting that increased levels of $\mathrm{HO}-$ 1 are associated with tumorigenesis [40-43]. An oncogenic microRNA, miR-155, targets Bachl and their interaction has been discussed in the context of leukemogenesis [44].

Despite the growing number of evidences that inhibition of Bachl may be beneficial in certain clinical situations [1, $26,28,29,31,45]$, the long-term, organismal response to Bach1 ablation has not yet been examined. Considering its distinct effects on ROS homeostasis and cell proliferation, Bach1 deficiency may affect the aging and/or life span in mice under normal conditions; ROS levels would decrease via the derepression of HO-1, and/or the p53-dependent cellular senescence would be increased by the enhanced activity of p53. The purpose of this study was to determine the lifelong effects of Bach1 deficiency on mice. We monitored cohorts of mice under typical laboratory conditions. We also generated Bach1; p53-double deficient mice to examine whether the Bach1 deficiency and accompanying overexpression of HO1 would affect tumor incidence in the absence of the main tumor suppressor $\mathrm{p} 53$. To investigate the possibility that some of the effects of Bach1 deficiency might be compensated for, we carried out an expression profiling of the liver, a major organ of the iron/heme metabolism, during aging. The overall results indicated that Bach1 was not necessary for the normal life course of mice, including longevity and tumorigenesis under the laboratory conditions. The apparent normal phenotypes of Bach1-deficient mice involved a transcriptomewide adaptation in the liver induced upon aging, which shows a novel gene regulatory mechanism compensating for the loss of Bach1. Based on our results, we discuss possible application of Bachl inhibition for a clinical treatment.

\section{Material and Methods}

2.1. Mice. Bach1-deficient mice were previously reported [18] and back-crossed to C57B6J at least 12 times. p53-deficient mice with C57B6J background were provided by Dr. Motoya Katsuki. Mice were fed ad libitum.

2.2. Genotyping. Four-week-old mice were used for genotype. Mouse DNA was extracted as previously reported [18]. PCRs were carried out using the following primers: Bachl-F 5' -CATGTGTGTTTGCAGGTCGA-3', Bach1 mutant-F 5' AGTAGGTGTCATTCTATTCTGGG-3', Bach1-R 5'-GTGGAAGTAGCTGCTGCACG-3', p53-F $5^{\prime}$-CACCTGCACAAGCGCCTCTC-3', and p53-R 5'-GCTGTCTCCAGACTCCTCTG-3'. PCR product of $\mathrm{p} 53$ amplicon was digested by EcoRI to discriminate the genotypes.

2.3. Antibodies for Flow Cytometry. The following fluorescent dye-conjugated monoclonal antibodies were purchased from BD Bioscience (Franklin Lakes, NJ) and used for flow cytometry and cell sorting (FACSCantoII or FACSAriaII): Sca-1 (D7), c-kit (2B8), Flt-3 (A2F10), and CD150 (TC1512F12.2). Biotinylated lineage antibodies CD3 (145-2C11), CD4 (GK1.5), CD8a (53-6.7), CD11b (M1/70), B220 (RA36B2), Gr-1 (RB6-8C5), NK1.1 (PK136), and Ter119 were revealed with streptavidin-PerCP or streptavidin-PerCP5.5.

2.4. Analysis of Intercellular ROS in HSCs. Bone marrow cells were collected by aspiration and $5 \times 10^{6}$ cells were stained with PE-Flt3, APC-Sca-1, APC-Cy7-c-kit, and PerCP-lineage antibodies. The cells were incubated with $5 \mu \mathrm{M}$ DCF-DA (Sigma) in $10 \%$ FBS IMDM (Gibco) at $37^{\circ} \mathrm{C}$ for $30 \mathrm{~min}$ and then analyzed by FACSCantoll (BD Bioscience) (52).

2.5. Gene Expression Profiling and Real-Time qPCR. All equipment and reagents used for the gene expression profiling were purchased from Agilent Technologies (Santa Clara, CA). Total RNA samples were isolated, amplified, labeled with cyanine-3 dye, and hybridized with Whole Mouse Genome Array $(4 \times 44 \mathrm{~K})$ slides exactly following the manufacturer's protocol. The analyses were carried out in 
triplicate. Genes expression data were analyzed using Genespring GX 12 (Agilent Technologies) and IPA 8 (Ingenuity Systems, Redwood City, CA) softwares. The difference in the genes expression was assessed by Volcano plots using moderated $t$-test with Benjamini-Hochberg FDR correction ( $\alpha=0.05)$, and 1.5-fold difference with corrected $P$ value $<0.05$ was considered significant. For pathway analysis and GO semantic analysis, enrichment with corrected $P$ value 0.0001 (Fisher's exact test, Bonferroni FDR correction) was considered significant. qPCRs were performed using a Light Cycler 2.0 instrument in the SYBR green format (Roche Diagnostics, Mannheim, Germany). Expression of $\beta$-actin was used as an internal control. The primer sequences for $\beta$ actin and Alas1 were published previously [46, 47].

2.6. Histological Analysis. The sections of formalin fixed paraffin embedded tissue samples were stained with hematoxylin and eosin or Prussian blue dye. The specimens were examined by an experienced pathologist.

2.7. Bone Marrow Transplantation. The 8-week-old CD45.1 congenic C57/B6 mice were subjected to lethal $\gamma$-irradiation in two doses of 500 rads each (for a total of 1000 rads) with 3 hours blank time and were injected with 100 sorted LT-HSCs $\left(\mathrm{Lin}^{-}, \mathrm{c}^{-\mathrm{Kit}^{+}}{ }^{+} \mathrm{Sca}_{-1}^{+}, \mathrm{Flt3}^{-}\right.$, and $\mathrm{CD} 150^{+}$) from wild-type or Bach1-deficient CD45.2 mice, in competition with $2 \times 10^{5}$ bone marrow mononuclear cells from CD45.1 and CD45.2 heteromice via a tail vein. Mice were treated with ampicillin $(30 \mathrm{mg} / \mathrm{mL})$ in the drinking water for 4 weeks. Peripheral blood cells (PBs) reconstitution by donor cells was monitored every 4 weeks. PBs were stained with fluorescent-conjugated antibodies specific for CD45.1, CD45.2, CD4, CD8, CD11b, Gr-1, and B220 and analyzed by a flow cytometry.

2.8. Statistical Analysis. Quantitative data except for the genes expression analysis were evaluated using JMP 10 (SAS Institute, Inc., Cary, NC). Log-rank test was used for analysis of survival curves. Student's $t$-test with Welch's correction was used for analysis of measurement of ROS level and bone marrow transplantation experiments. Fisher's exact test was used for comparison of death rates among Bach1; p53 mutant mice. $P$ values less than 0.05 were considered statistically significant in all tests.

\section{Results and Discussion}

3.1. Life Span of Bach1-Deficient Mice. As reported previously [18], Bach1-deficient mice were born according to Mendelian ratio with normal fertility being indistinguishable from wildtype mice. To examine the effect of Bach1 deficiency during the life span, cohorts of Bach1-deficient and wild-type mice were followed up under pathogen-free condition. Life span was not affected (log-rank test, $P=0.93$ ) by Bach1 deficiency (Figure 1(a)). We used body weight as a basic indicator of mice health and general condition. Logistic regression model indicated that age $(P=0.045)$ and $\operatorname{sex}(P<0.0001)$ but not genotype $(P=0.45)$ were significantly associated with body weight (Figure 1(b)). No difference was found by the histological analysis of major organs such as kidney and spleen in around 100-week-old mice (Figure 1(c)). The thickness of skin from ear and villi of small intestine in aging Bach1-deficient mice were similar to those of wild-type mice (Figure 1(c)). Because HO-1 liberates iron from heme, we expected that Bach1-deficient mice would show enhanced iron deposition. However, there was no apparent change in morphology, iron deposits, and concentration of heme in the liver of aging Bach1-deficient mice compared with those in wild-type mice (Figure 1(d)). Our results demonstrated that Bach1 deficiency did not affect the phenotypes of aging and life span.

3.2. Effect of Bach1 Deficiency on Hematopoietic Stem Cells. We evaluated Bachl-deficient HSCs since these cells are sensitive to increased levels of ROS and become senescent under such conditions [48, 49]. HSCs isolated from Bach1deficient and wild-type mice (around 10 and 100 weeks) were stained with DCFDA, which was converted to fluorescent DCF within cells by ROS including hydrogen peroxide (Figure 2(a)). To quantify levels of fluorescence, we showed the averages of median in the three independent experiments (Figure 2(b)). The levels of ROS were similar irrespective of the genotype and age of the mice, indicating that Bach1 deficiency did not apparently influence the metabolism of ROS in the HSCs. While those in young Bach1-deficient mice were comparable to wild-type mice, the numbers of HSCs in aged Bach1-deficient mice increased (Figure 2(c)). Therefore, it is speculated that Bach1 would affect proliferation and/or maintenance of HSCs during aging. To more directly assess the function of HSCs, transplantations of young wild-type or Bach1-deficient LT-HSCs to lethally irradiated wild-type mice were performed (Figure 2(b)). No obvious difference in the chimerism was observed irrespective of the genotypes. These data demonstrated that Bach1 deficiency did not apparently affect ROS metabolism and the reconstitution activity of HSCs under the normal physiological condition.

We conclude that cellular senescence and its associated phenotype were not accelerated to a degree affecting organismal soundness in Bachl-deficient mice kept under the nonstressed condition. We need to examine whether Bach1 deficiency modulates ROS metabolism when mice are challenged with oxidative stress. The results suggest that a targeting of Bachl in medical treatment is acceptable for acute and chronic injuries without any long-term side effect as shown in several papers $[1,26,28,29,31,45]$.

3.3. Effect of Bach1 Deficiency on Tumor Formation in the p53-Null Mice. Bach1 deficiency in fibroblasts leads to the resistance to transformation by the H-Ras ${ }^{\mathrm{V} 12}$ oncogene, possibly by means of mitigating ROS accumulation induced by $\mathrm{H}$-Ras ${ }^{\mathrm{V} 12}$. Also Bach1-deficient mice are less susceptible to 4-nitroquinoline-1-oxide- (4-NQO-) induced tongue carcinoma than wild-type mice [39]. These observations suggest that higher HO-1 levels may be causal for the tumor-suppressive phenotype of Bach1 deficiency in this experimental model. On the other hand, it has recently been reported that an overexpression of $\mathrm{HO}-1$ is associated 


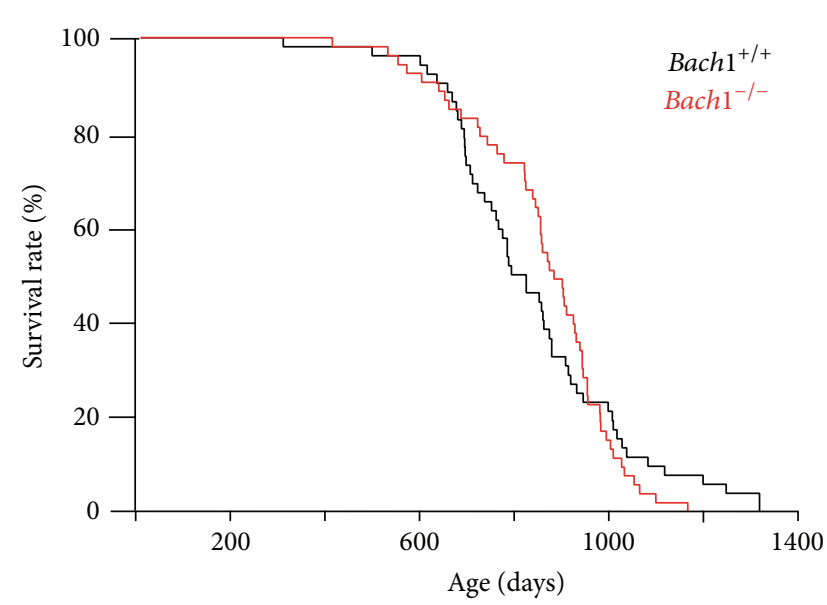

(a)

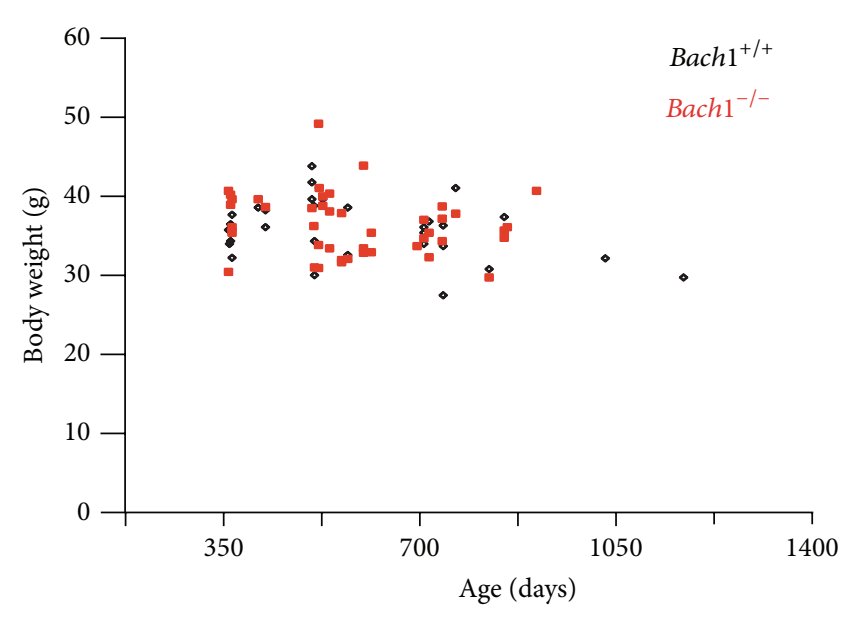

(b)
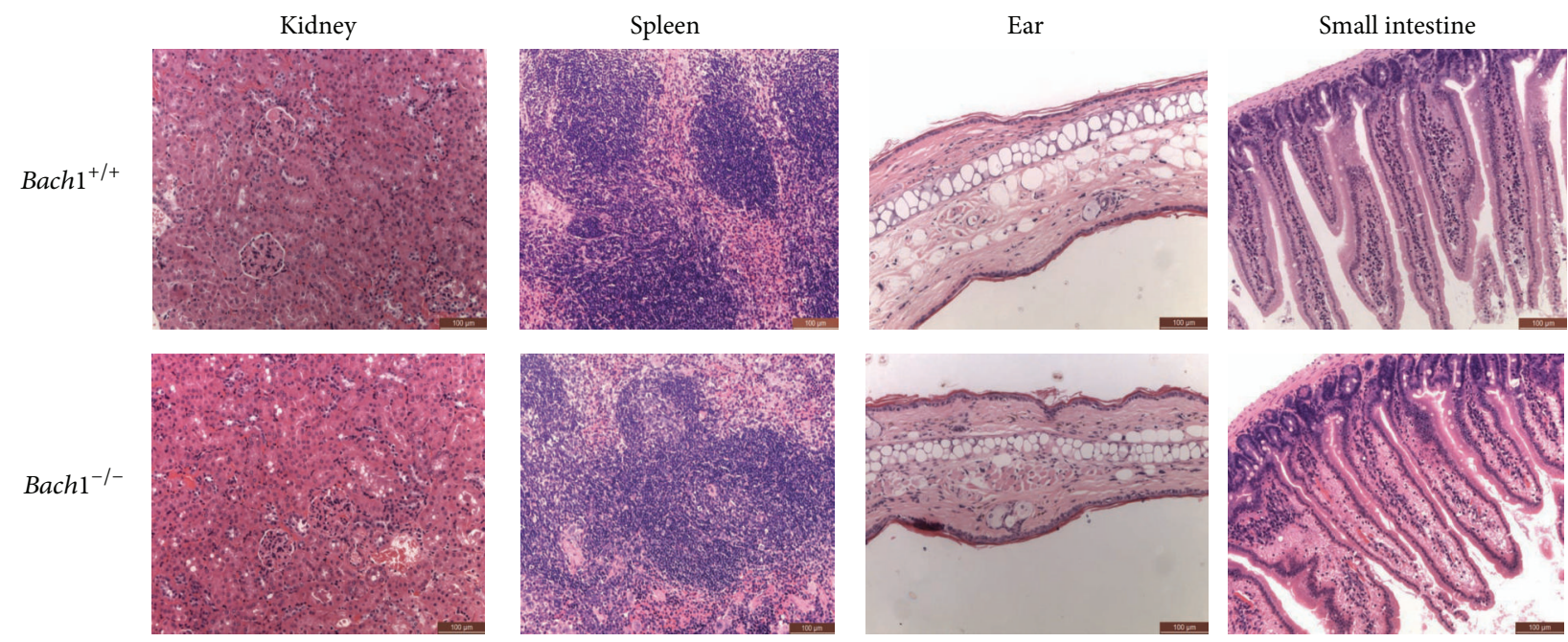

(c)
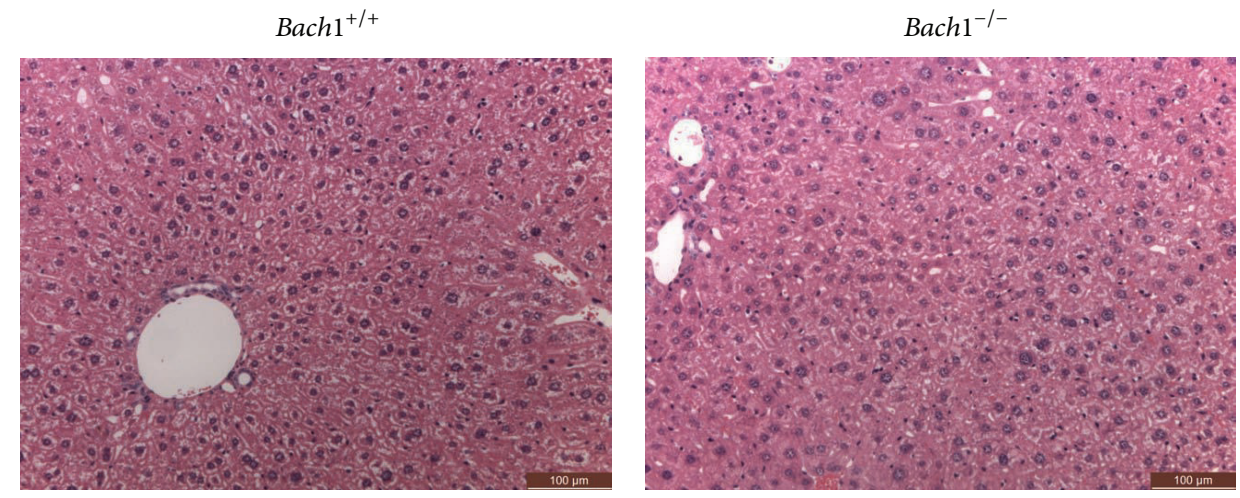

(d)

Figure 1: Effects of Bach1 deficiency on life span. (a) 52 wild-type and 53 Bach1-deficient mice were monitored for their lives. The average life span was $846.1 \pm 199.3$ days and $867.5 \pm 154.0$ days, respectively. (b) The body weight of wild-type and Bachl-deficient mice is plotted against the age. (c) The histology of kidney, spleen, skin of ear, and small intestine in wild-type and Bach1-deficient mice. Representative images are shown among three mice of each genotype. Scale bars are $100 \mu \mathrm{m}$. (d) The histology of liver in wild-type and Bach1-deficient mice. Representative images are shown among three mice of each genotype. Scale bars are $100 \mu \mathrm{m}$. 


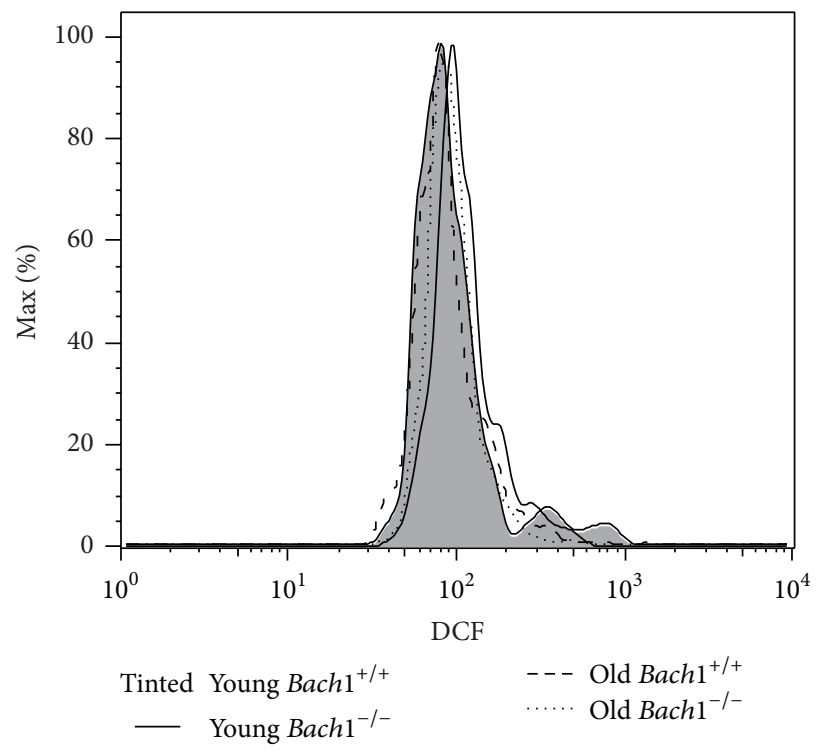

(a)

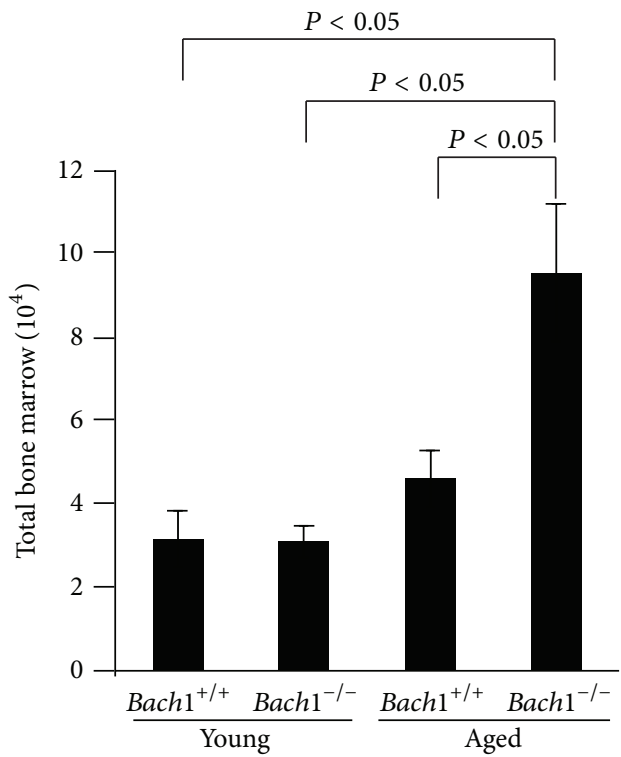

(c)

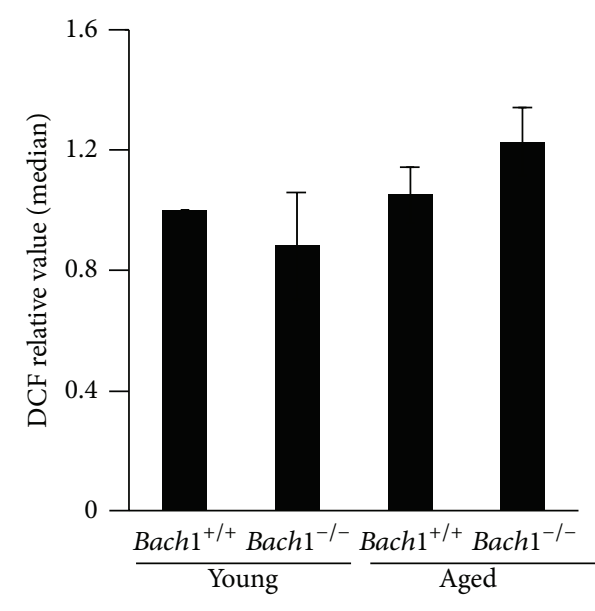

(b)

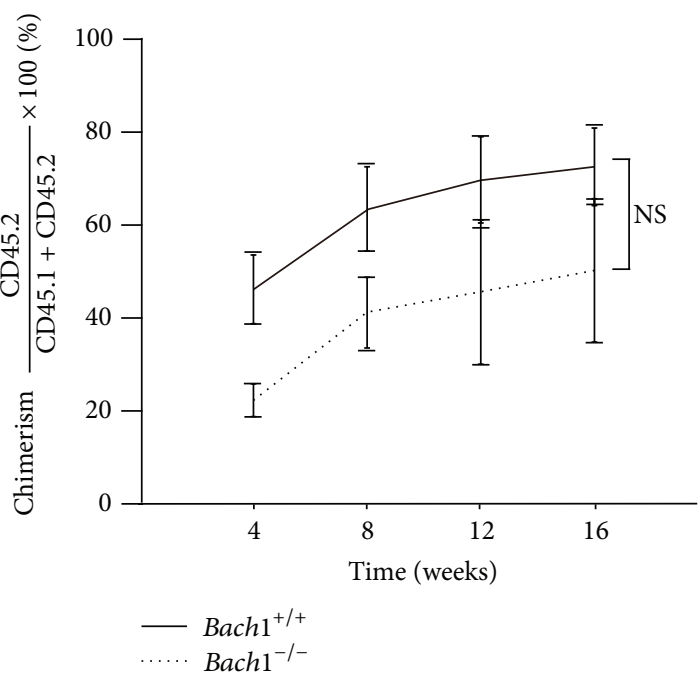

(d)

Figure 2: Effects of Bach1 deficiency in HSCs. (a) The levels of oxidized DCFDA in HSCs in young and aged, wild-type and Bach1-deficient mice. A representative result from three independent experiments is shown. (b) The averages of median of the experiments in the three experiments of (a). The results are expressed as mean \pm S.D $(n=3)$; relative values to young wild-type HSCs in each experiment. (c) The numbers of HSCs in young and aged, wild-type and Bachl-deficient mice. The results are expressed as mean \pm S.D $(n=3)$. ${ }^{*} P<0.05$. (d) Transplantations of bone marrow LT-HSCs between wild-type and Bach1-deficient mice. The chimerism data from five wild-type and four Bach1-deficient mice are presented as means \pm S.E.M. The chimerism was calculated by a formula, CD $45.2 \times 100 /(C D 45.1+$ CD 45.2$)(\%)$.

with certain types of cancers $[40-43,50]$. Therefore, we examined whether Bachl or its absence would contribute to spontaneous tumorigenesis. We generated cohorts of Bachldeficient mice and Bach1- and p53-double deficient $\left(\mathrm{BaCh1}^{-1-}\right.$; $p 53^{-/-}$) mice because $p 53$ deficiency induces intrinsic onset of tumorigenesis [51, 52]. All of the combinatorial genotypes were viable and indistinguishable to one another. The absence of obvious genetic interaction between Bachl and p53 during embryonic development and neonatal period was not contradictory to our previous report that Bachl inhibited p53 [33] and showed that their combined effects could be assessed in the tumorigenesis at adult stages. 


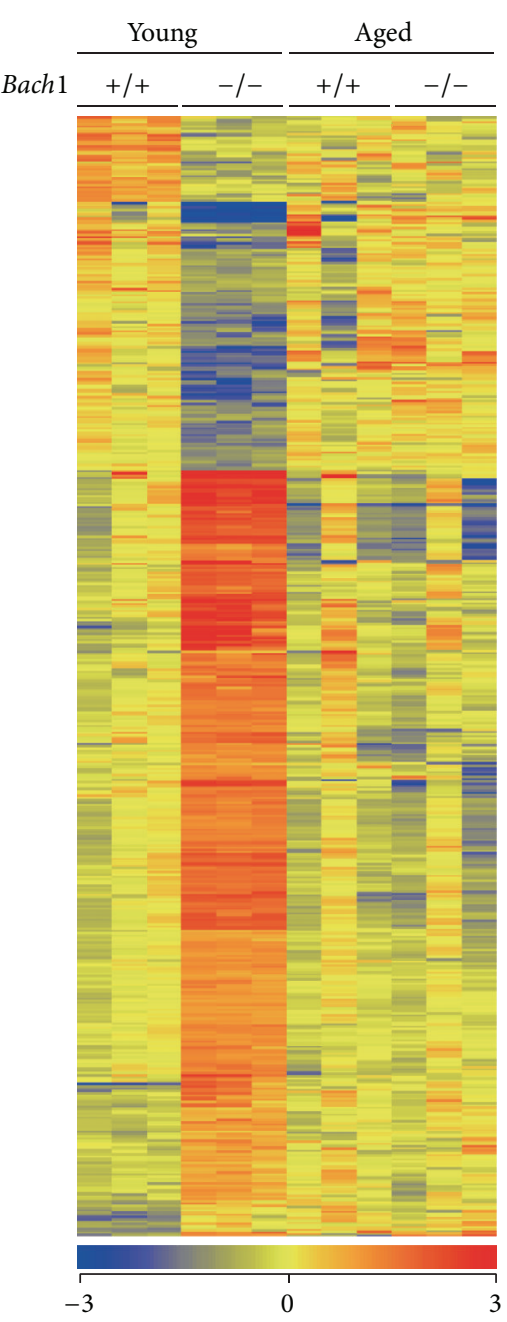

(a)

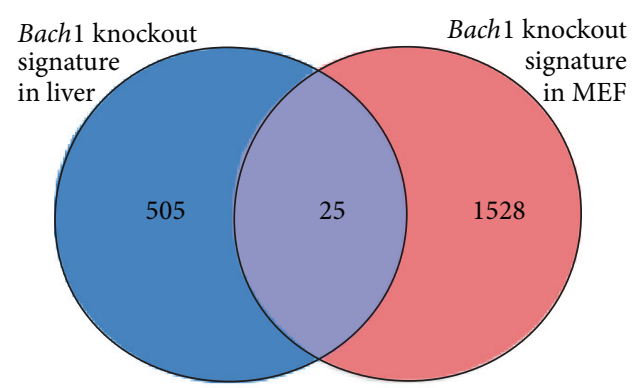

(b)

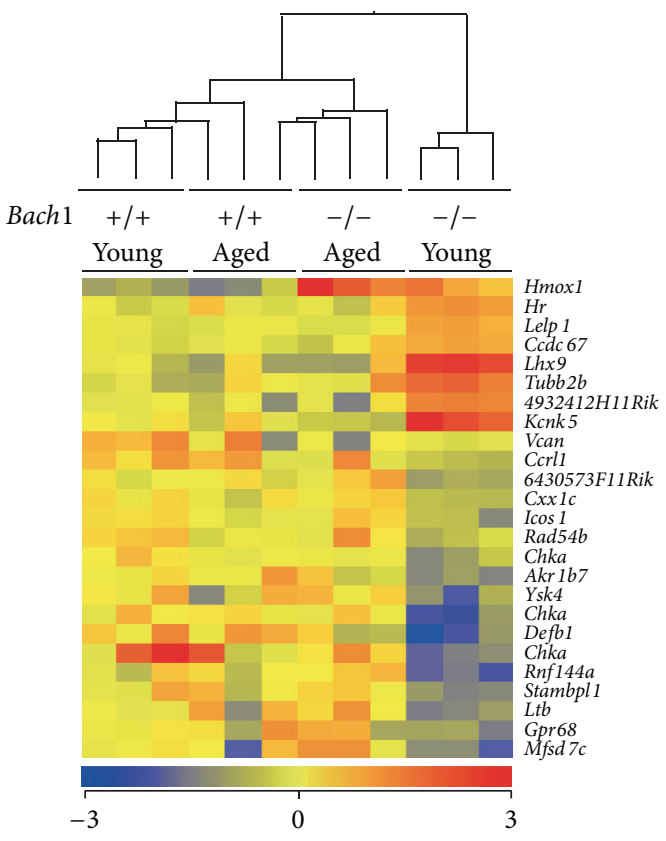

(c)

Figure 3: Effects of age and Bach1 deficiency on gene expressions in mice. (a) Heat map visualizations of the 530 entities, differentially expressed in the livers of young Bach1-deficient compared with young wild-type mice. Three mice were used for each group. Here and elsewhere the data for heat maps are normalized and represented as median-centered log-transformed values, using average linkage clustering on entities. Red and blue correspond to high and low expression, respectively, compared with the experiment-wide median. (b) Venn diagram shows overlap between the Bach1 knockout gene expression signature in liver and the previously published [39] Bach1 knockout signature in MEF. (c) Heat map visualizations of the 25 entities common for both signatures. Hierarchical clustering on entities and conditions.

p53-deficient mice die earlier than wild-type ones due to frequent tumor formation [51, 52]. Mice of various genotypes including Bachl ${ }^{-/-} ; \mathrm{p5}^{-/-}$were followed up for thirty weeks during which most of $p 53$-deficient mice succumbed to cancers (Table 1). While all of the wild-type mice were alive by the end of observation, many of the p53-deficient mice died due to spontaneously developed tumors. Bach1 deficiency did not apparently reduce the death rate in $p 53$-deficient mice (Fisher's exact test; $P=0.6$ ).

Considering functions of Bachl, we need to clarify the possible involvement of Bachl and $\mathrm{HO}-1$ in specific tumors by using of different tumor initiation models. Since cellular senescence would not occur in the absence of p53, Bachl may not affect transformation under the experimental conditions we used. Likewise, the involvement of HO-1 in cancer may
TABLE 1: Death rate before age of thirty weeks ${ }^{\mathrm{a}}$.

\begin{tabular}{cccc}
\hline Genotype & & $p 53$ & \\
& $+/+$ & $+/-$ & $-/-$ \\
\hline Bach1 & & & \\
$+/+$ & $0 / 2$ & $0 / 4$ & $7 / 10$ \\
$+/-$ & $0 / 11$ & $0 / 19$ & $6 / 11$ \\
$-/-$ & $0 / 9$ & $1 / 9$ & $2 / 5$ \\
\hline
\end{tabular}

${ }^{\mathrm{a}}$ The denominator is the number of observed littermates and the numerator is the number of dead littermates born from $\mathrm{Bachl}^{+/-} ; p 53^{+/-}$parents $(n=$ $80)$.

depend on genetic changes underlying the transformation process $[40-43,50]$. It should be noted that HO-1 can accelerate tumor growth and affect malignancy of the tumor [53]. 


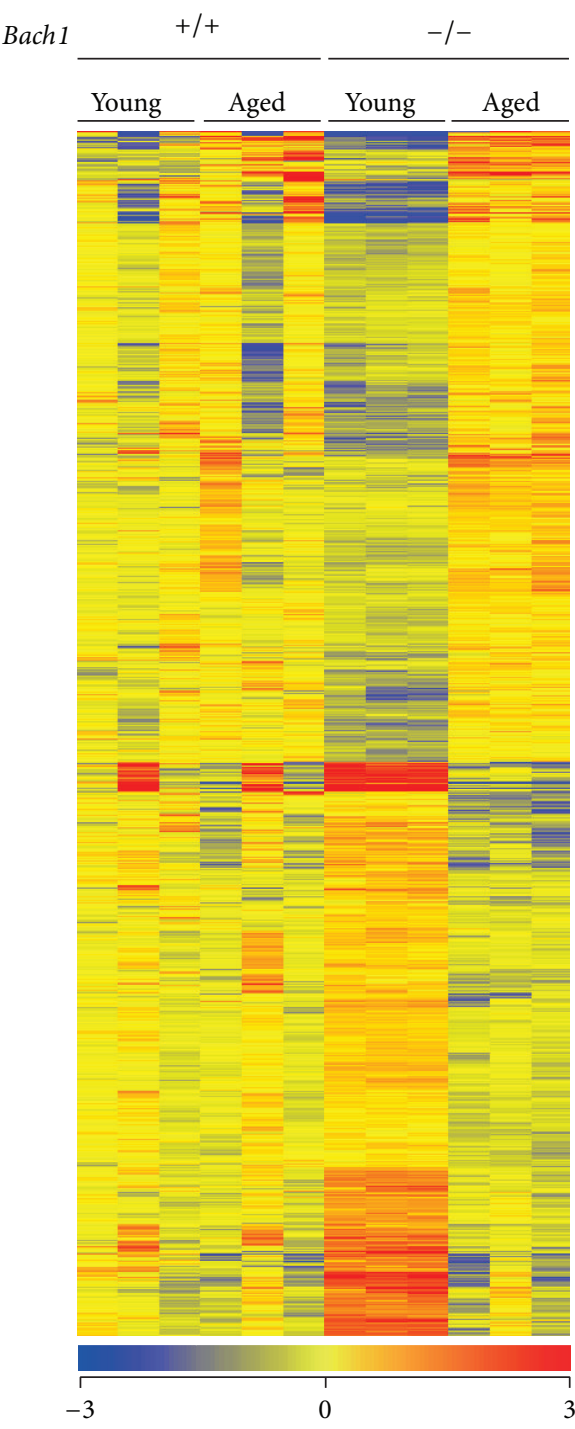

(a)

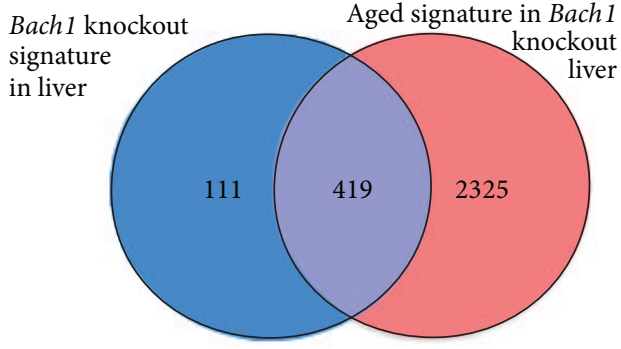

(b)

FIGURE 4: The effect of aging on genes expression profile in Bach1-deficient mice liver. (a) Heat map visualizations of the 2744 entities, differentially expressed in the livers of young Bachl-deficient mice compared with aged ones. (b) Venn diagram shows overlap between the Bach1 knockout genes expression signatures (Figure ??) and aging signature in Bach1-deficient liver.

Hence, we need to assess impacts of Bachl deficiency in terms of tumor incidence, spread, and progression as well. Notwithstanding these remaining issues, our current observations indicate that Bachl does not play a critical modifying role in incidence of death due to tumor in the context of p53-null condition.

3.4. Transcriptome-Wide Adaptation in Bach1-Deficient Mice. One possible explanation for the above observations was that the loss of Bachl was compensated by other genes and/or pathways. To address this possibility, we focused on gene expression profiles as an intermediary trait. Liver samples were used for this analysis since it is one of the major organs for the metabolism of heme, which is a ligand of Bach1 [19, 54]. We compared the gene expression profiles of the livers of wild-type and Bach1-deficient mice along the course of aging. We identified a Bach1 knockout signature comprised of 530 entities (1.7\% of 31433 examined) which were differentially expressed in the livers of 8-week-old Bach1-deficient mice compared with wild-type mice of the same age (Figure ?? and see Supplementary Table 1 in Supplementary Material available online at http://dx.doi.org/10.1155/2014/757901). Interestingly, the genes expression signature of the Bach1deficient livers disappeared when examined at 100 weeks of age (Figure ??). The 530 gene sets showed overlap with previously published Bach1 knockout signature in MEFs (25 gene entities, Figure ??) [39]. To our surprise, hierarchical clustering of the 25 entities common for both signatures demonstrated that all genes except for Hmoxl returned to the normal levels similar to those in wild-type livers (Figure ??). 


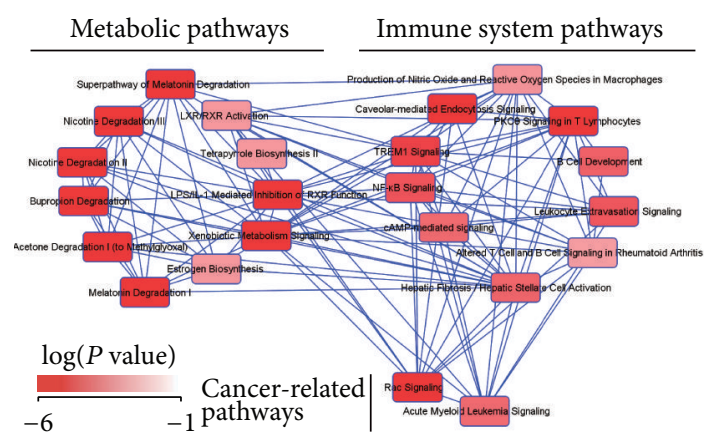

FIGURE 5: Pathway analysis of the genes which were affected by aging in the livers of Bach1-deficient mice. Network presentation of the canonical pathways, components of which were significantly enriched in the aging signature of Bachl-deficient mice liver. The intensity of red nodes color indicates the degree of significance (Fisher's exact test). The lines indicate overlap between pathways.

While the expression of Bach1-regulated genes is deregulated in the absence of Bach1 in the liver, their expression can be modulated to a normal pattern upon aging.

To understand which part of the transcriptome was affected in young Bachl-deficient mice and resolved with age, we analyzed the aging signature in wild-type and Bach1deficient animals. A relatively small number of genes are known to be affected by aging in mouse liver [55]. There was no statistically significant difference in genes expression in the livers of the aged wild-type mice compared with those of young wild-type mice. In contrast, expression of 2744 entities ( $8.7 \%$ of 31433 examined) was significantly altered by aging in Bachl-deficient livers (Figure 4(a)). Roughly half of them were upregulated with aging, whereas the other half was repressed upon aging (Figure 4(a) and Supplementary Table 2). The set of genes repressed in the aged Bach1-deficient livers could include direct transcriptional target of Bach1. Their reductions in the expression levels upon aging suggest that the activities of transcription factors responsible for their expression may recede upon aging. On the other hand, the genes which were induced upon aging in Bachl-deficient livers may represent indirect target genes of Bachl and may require specific activating signals that set off upon aging. Approximately $80 \%$ of the genes which were differentially expressed in young wild-type and Bach1-deficient mice and then reverted to the normal levels (Figure ??) belonged to the genes altered upon aging in Bachl-deficient mice (Figure 4(b)), indicating that the genes induced or reduced during aging in Bach1-deficient mice may compensate for the Bachl deficiency and may contribute to the apparent lack of any phenotypic alteration in the long term.

To understand the relationship between the transcriptome alterations in Bachl-deficient livers and organism functions, we performed pathway analysis (IPA software, Ingenuity Systems) on the list of entities expression of which was significantly altered by aging in Bachl-deficient mice (Figure 4(a) and Supplementary Table 2). We identified two clearly distinguished but interconnected modules in the gene regulation network: metabolic pathways module and immune system signaling module, the latter of which also included two tumor-related pathways (Figure 5). Among the significantly enriched pathways, the highest enrichment scores were associated with metabolic pathways (Figure 6(a); genes are listed in Figure 6(b)). These genes showed little change in wild-type mice but showed either increases or decreases in Bachl-deficient mice upon aging (Figure 6(b)). Semantic analysis of these genes and their functions revealed significant enrichment of the genes responsible for catalytic activity of oxidoreductases including cytochrome P450 monooxygenase system (Figure 6(c)). A significant portion of oxidoreductases genes were downregulated in the liver of young Bachl-deficient mice compared with those of young wild-type mice, and this alteration disappeared upon aging (Figure 6(d)). Many of the oxidoreductases genes encode hemoproteins. Remarkably, we found that expression of Alasl, the rate-limiting enzyme in the heme synthetic pathway, was upregulated in the liver tissue of the young Bachldeficient mice (Figure 6(e)). The heme biosynthesis pathway may be activated in Bach1-deficient mice when they are young, compensating for the higher expression of HO-1 and therefore enhanced degradation of heme. It has been reported previously that the enzymatic activity of Alas1 decreases upon aging in several tissues including the liver in rats [56]. While this particular paper assessed the enzymatic activity of Alas using aging rats, their results suggest that the expression of Alas 1 mRNA would decrease upon aging [56]. While we did not observe such an alteration in the wild-type mice, Alas 1 mRNA indeed decreased upon aging in Bach1-deficient mice. Genes involved in aging may affect the expression of Alas1 and such a response may have been easily observed in Bachl-deficient liver cells due to the higher expression of Alas 1 mRNA in the young Bach1-deficient mice compared with corresponding wild-type mice. The reduction of Alas1 mRNA may indirectly facilitate the transcriptome adaptation in Bach1-deficient mice by altering the heme synthesis.

The observed transcriptome-wide adaptation in the gene regulatory network upon aging may be one possible mechanism to suppress a long-term effect of Bachl deficiency and $\mathrm{HO}-1$ overexpression. Any side effect of HO-1 overexpression in the absence of Bachl could be avoided by the transcriptome adaptation. Considering that Bach1 is primarily a repressor of gene expression, the activities of activating transcription factors such as Nrf2 may affect the expression levels of downstream genes in the absence of Bachl. Upon aging, such activators may be inhibited, resulting in a stable and harmless transcriptome. This hypothesis posits that ROS levels would decrease in the liver upon aging. However, we did not see any significant change in the levels of ROS in HSCs upon aging. Since the metabolism of ROS may be differentially regulated upon aging depending on tissues, we need to compare ROS levels in the liver as well.

\section{Conclusions}

Here we showed that Bachl did not affect phenotypes of aging or life span of mice. At the transcriptome level, Bach1 deficiency itself affected expression of many genes, including 


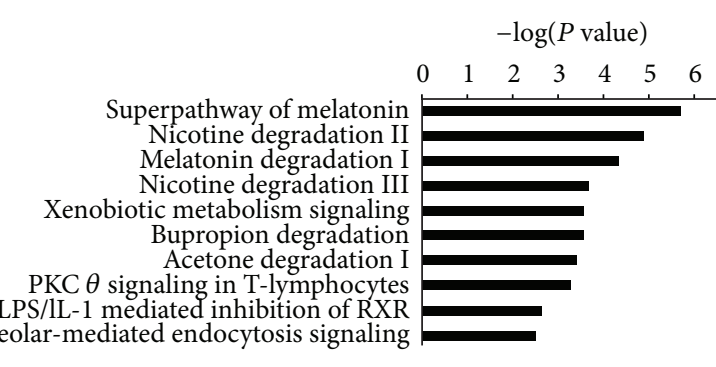

(a)

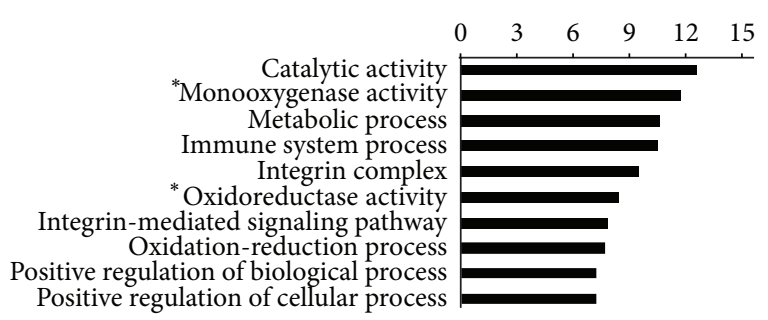

(c)
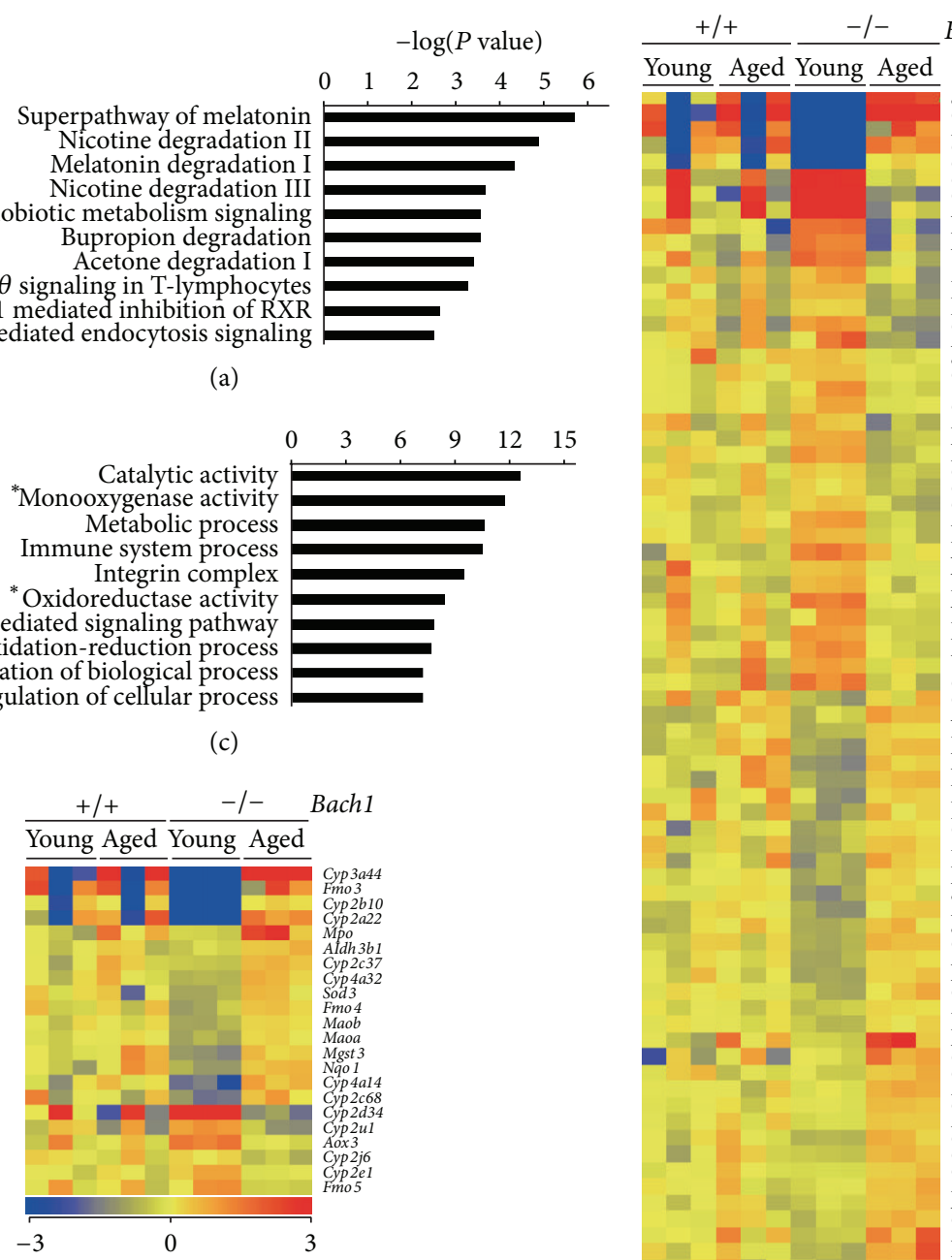

Bach1

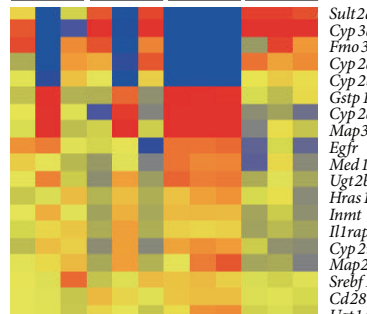
Sult $2 a 1$
Cyp3a44 Cyp $3 a 44$
Fyo3
Cyp $2 a 22$ Cyp 2022
Cypt2b10
Cspp 2 2d34
Map $3 k 9$ Map $3 k 9$
Egfr Caveolar-mediated endor
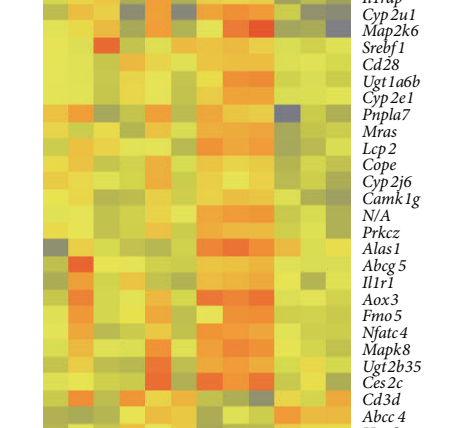

(d)

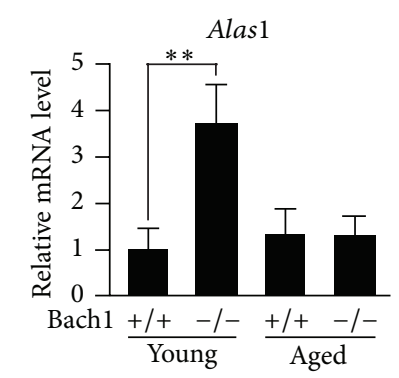

(e)

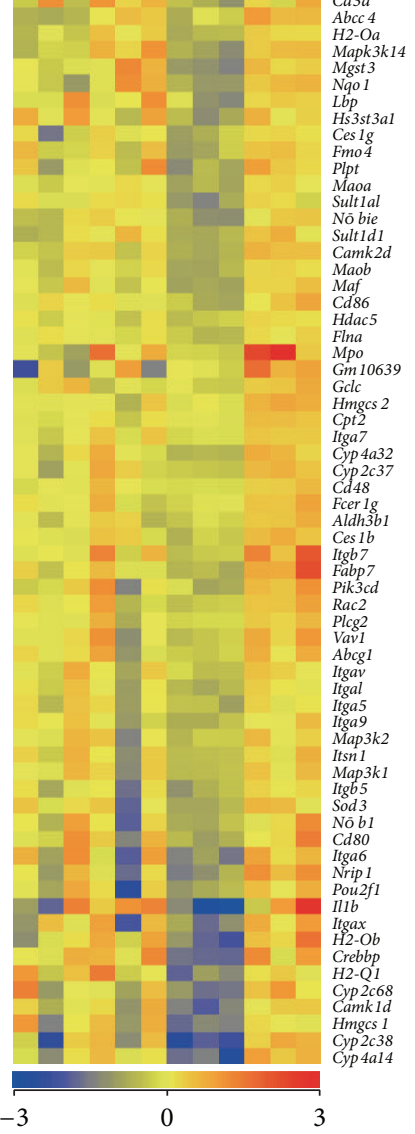

(b)

FIGURE 6: Semantic analysis of the genes which were affected by aging in the livers of Bach1-deficient mice. (a) Ten most significantly enriched canonical pathways are listed in significance order (Fisher's exact test). (b) Heat map visualization of the genes from ten most significantly enriched canonical pathways. (c) GO analysis of the genes from ten most significantly enriched canonical pathways. The GO terms are listed in enrichment significance order (Fisher's exact test). (d) Heat map visualizations of the genes corresponding to the GO terms ${ }^{*}$ monooxygenase activity and * oxidoreductase activity in the panel (c). (e) mRNA levels of Alasl normalized with beta-actin. The results are expressed as mean \pm S.D $(n=3) .{ }^{* *} P<0.05$. 
Hmox1, cytochrome P450 monooxygenase system, and Alas1. However, the difference in the expression of all these genes except for Hmoxl disappeared when the mice aged. Our findings suggest that long-term targeting of Bach1, retaining high expression levels of Hmoxl during the life span, is safe and free from adverse effects owing to compensation at the level of transcriptome. However, although we did not observe any detrimental effect of Bachl deficiency and the longterm overexpression of HO-1 under the normal conditions, it remains possible that Bachl becomes critical under specific conditions. This is a rational inference considering its evolutionary conservation among vertebrates [22].

$\begin{array}{ll}\text { Abbreviations } \\ \text { 4-NQO: } & \text { 4-Nitroquinoline-1-oxide } \\ \text { Bach1: } & \text { BTB and CNC homology } 1 \\ \text { CO: } & \text { Carbon monoxide } \\ \text { DCFDA: } & \text { Dichlorodihydrofluorescein diacetate } \\ \text { HDAC1: } & \text { Histone deacetylase } 1 \\ \text { HSCs: } & \text { Hematopoietic stem cells } \\ \text { HO-1: } & \text { Heme oxygenase-1 } \\ \text { MARE: } & \text { Maf-recognition element } \\ \text { MEFs: } & \text { Mouse embryonic fibroblasts } \\ \text { PBs: } & \text { Peripheral blood cells } \\ \text { ROS: } & \text { Reactive oxygen species. }\end{array}$

\section{Conflict of Interests}

The authors declare that there is no conflict of interests regarding the publication of this paper.

\section{Acknowledgments}

The interpretation of the data was enriched by discussions with Dr. M. Ono (Tohoku University). Part of this study was supported by Biomedical Research Core of Tohoku University School of Medicine. This work was supported by Grants-in-aid and the Network Medicine Global-COE Program from the Ministry of Education, Culture, Sports, Science and Technology, Japan. Critical initiative support was from Takeda Foundation. Restoration of laboratory damage from 2011 Tohoku earthquake was supported in part by the Astellas Foundation for Research on Metabolic Disorders, Banyu Foundation, Naito Foundation, A. Miyazaki, and A. Iida.

\section{References}

[1] P. D. Adams, "Healing and hurting: molecular mechanisms, functions, and pathologies of cellular senescence," Molecular Cell, vol. 36, no. 1, pp. 2-14, 2009.

[2] D. Harman, "Aging: a theory based on free radical and radiation chemistry," Journal of Gerontology, vol. 11, no. 3, pp. 298-300, 1956.

[3] T. Finkel and N. J. Holbrook, "Oxidants, oxidative stress and the biology of ageing," Nature, vol. 408, no. 6809, pp. 239-247, 2000.

[4] L. E. Otterbein, M. P. Soares, K. Yamashita, and F. H. Bach, "Heme oxygenase-1: unleashing the protective properties of heme," Trends in Immunology, vol. 24, no. 8, pp. 449-455, 2003.

[5] S. W. Ryter and A. M. K. Choi, "Heme oxygenase-1: redox regulation of a stress protein in lung and cell culture models," Antioxidants and Redox Signaling, vol. 7, no. 1-2, pp. 80-91, 2005.

[6] S. Shibahara, T. Kitamuro, and K. Takahashi, "Heme degradation and human disease: diversity is the soul of life," Antioxidants and Redox Signaling, vol. 4, no. 4, pp. 593-602, 2002.

[7] K. D. Poss and S. Tonegawa, "Reduced stress defense in heme oxygenase 1-deficient cells," Proceedings of the National Academy of Sciences of the United States of America, vol. 94, no. 20, pp. 10925-10930, 1997.

[8] D. M. Suttner, K. Sridhar, C. S. Lee, T. Tomura, T. N. Hansen, and P. A. Dennery, "Protective effects of transient HO-1 overexpression on susceptibility to oxygen toxicity in lung cells," American Journal of Physiology. Lung Cellular and Molecular Physiology, vol. 276, no. 3, pp. L443-L451, 1999.

[9] S. R. Vulapalli, Z. Chen, B. H. L. Chua, T. Wang, and C.-S. Liang, "Cardioselective overexpression of HO-1 prevents I/Rinduced cardiac dysfunction and apoptosis," American Journal of Physiology. Heart and Circulatory Physiology, vol. 283, no. 2, pp. H688-H694, 2002.

[10] N. Yun, H.-A. Eum, and S.-M. Lee, "Protective role of heme oxygenase-1 against liver damage caused by hepatic ischemia and reperfusion in rats," Antioxidants and Redox Signaling, vol. 13, no. 10, pp. 1503-1512, 2010.

[11] M. Giriş, Y. Erbil, S. Öztezcan et al., "The effect of heme oxygenase-1 induction by glutamine on radiation-induced intestinal damage: the effect of heme oxygenase-1 on radiation enteritis," American Journal of Surgery, vol. 191, no. 4, pp. 503509, 2006.

[12] H. M. Schipper, "Heme oxygenase-1: role in brain aging and neurodegeneration," Experimental Gerontology, vol. 35, no. 6-7, pp. 821-830, 2000.

[13] J. Sun, M. Brand, Y. Zenke, S. Tashiro, M. Groudine, and K. Igarashi, "Heme regulates the dynamic exchange of Bach1 and NF-E2-related factors in the Maf transcription factor network," Proceedings of the National Academy of Sciences of the United States of America, vol. 101, no. 6, pp. 1461-1466, 2004.

[14] J. Alam, J. Cai, and A. Smith, "Isolation and characterization of the mouse heme oxygenase-1 gene. Distal 5 ' sequences are required for induction by heme or heavy metals," Journal of Biological Chemistry, vol. 269, no. 2, pp. 1001-1009, 1994.

[15] J. Alam, S. Camhi, and A. M. K. Choi, "Identification of a second region upstream of the mouse heme oxygenase- 1 gene that functions as a basal level and inducer-dependent transcription enhancer," Journal of Biological Chemistry, vol. 270, no. 20, pp. 11977-11984, 1995.

[16] C. T. Wagner, W. Durante, N. Christodoulides, J. D. Hellums, and A. I. Schafer, "Hemodynamic forces induce the expression of heme oxygenase in cultured vascular smooth muscle cells," Journal of Clinical Investigation, vol. 100, no. 3, pp. 589-596, 1997.

[17] K. Igarashi and J. Sun, "The heme-Bach1 pathway in the regulation of oxidative stress response and erythroid differentiation," Antioxidants and Redox Signaling, vol. 8, no. 1-2, pp. 107-118, 2006.

[18] J. Sun, H. Hoshino, K. Takaku et al., "Hemoprotein Bach1 regulates enhancer availability of heme oxygenase-1 gene," EMBO Journal, vol. 21, no. 19, pp. 5216-5224, 2002.

[19] K. Ogawa, J. Sun, S. Taketani et al., "Heme mediates derepression of Maf recognition element through direct binding to transcription repressor Bach1," EMBO Journal, vol. 20, no. 11, pp. 2835-2843, 2001. 
[20] K. Igarashi, H. Hoshino, A. Muto et al., "Multivalent DNA binding complex generated by small Maf and Bachl as a possible biochemical basis for $\beta$-globin locus control region complex," Journal of Biological Chemistry, vol. 273, no. 19, pp. 11783-11790, 1998.

[21] T. Oyake, K. Itoh, H. Motohashi et al., "Bach proteins belong to a novel family of BTB-basic leucine zipper transcription factors that interact with MafK and regulate transcription through the NF-E2 site," Molecular and Cellular Biology, vol. 16, no. 11, pp. 6083-6095, 1996.

[22] K. Igarashi and M. Watanabe-Matsui, "Wearing red for signaling: the heme-bach axis in heme metabolism, oxidative stress response and iron immunology," Tohoku Journal of Experimental Medicine, vol. 232, no. 4, pp. 229-253, 2014.

[23] K. Itoh, K. Igarashi, N. Hayashi, M. Nishizawa, and M. Yamamoto, "Cloning and characterization of a novel erythroid cell-derived CNC family transcription factor heterodimerizing with the small Maf family proteins," Molecular and Cellular Biology, vol. 15, no. 8, pp. 4184-4193, 1995.

[24] T. Ishii, K. Itoh, S. Takahashi et al., "Transcription factor Nrf2 coordinately regulates a group of oxidative stress-inducible genes in macrophages," Journal of Biological Chemistry, vol. 275, no. 21, pp. 16023-16029, 2000.

[25] J. Alam, D. Stewart, C. Touchard, S. Boinapally, A. M. K. Choi, and J. L. Cook, "Nrf2, a Cap'n'Collar transcription factor, regulates induction of the heme oxygenase-1 gene," Journal of Biological Chemistry, vol. 274, no. 37, pp. 26071-26078, 1999.

[26] Y. Yano, R. Ozono, Y. Oishi et al., "Genetic ablation of the transcription repressor Bach1 leads to myocardial protection against ischemia/reperfusion in mice," Genes to Cells, vol. 11, no. 7, pp. 791-803, 2006.

[27] A. Harusato, Y. Naito, T. Takagi et al., "Inhibition of Bach1 ameliorates indomethacin-induced intestinal injury in mice," Journal of Physiology and Pharmacology, vol. 60, pp. 149-154, 2009.

[28] T. Tanimoto, N. Hattori, T. Senoo et al., "Genetic ablation of the Bach1 gene reduces hyperoxic lung injury in mice: role of IL-6," Free Radical Biology and Medicine, vol. 46, no. 8, pp. 1119-1126, 2009.

[29] A. Iida, K. Inagaki, A. Miyazaki, F. Yonemori, E. Ito, and K. Igarashi, "Bach1 deficiency ameliorates hepatic injury in a mouse model," Tohoku Journal of Experimental Medicine, vol. 217, no. 3, pp. 223-229, 2009.

[30] S. Mito, R. Ozono, T. Oshima et al., "Myocardial protection against pressure overload in mice lacking bachl, a transcriptional repressor of heme oxygenase-1," Hypertension, vol. 51, no. 6, pp. 1570-1577, 2008.

[31] S. Omura, H. Suzuki, M. Toyofuku, R. Ozono, N. Kohno, and K. Igarashi, "Effects of genetic ablation of Bach1 upon smooth muscle cell proliferation and atherosclerosis after cuff injury," Genes to Cells, vol. 10, no. 3, pp. 277-285, 2005.

[32] A. Y.-L. So, Y. Garcia-Flores, A. Minisandram et al., "Regulation of APC development, immune response, and autoimmunity by Bach1/HO-1 pathway in mice," Blood, vol. 120, no. 12, pp. 24282437, 2012.

[33] Y. Dohi, T. Ikura, Y. Hoshikawa et al., "Bach1 inhibits oxidative stress-induced cellular senescence by impeding p53 function on chromatin," Nature Structural and Molecular Biology, vol. 15, no. 12, pp. 1246-1254, 2008.

[34] J. Campisi, "Cellular senescence as a tumor-suppressor mechanism," Trends in Cell Biology, vol. 11, no. 11, pp. S27-S31, 2001.
[35] M. Collado, J. Gil, A. Efeyan et al., "Tumour biology: senescence in premalignant tumours," Nature, vol. 436, no. 7051, p. 642, 2005.

[36] A. J. Giaccia and M. B. Kastan, "The complexity of p53 modulation: emerging patterns from divergent signals," Genes and Development, vol. 12, no. 19, pp. 2973-2983, 1998.

[37] K. Ota, Y. Dohi, A. Brydun, A. Nakanome, S. Ito, and K. Igarashi, "Identification of senescence-associated genes and their networks under oxidative stress by the analysis of Bachl," Antioxidants and Redox Signaling, vol. 14, no. 12, pp. 2441-2451, 2011.

[38] H. Nishizawa, K. Ota, Y. Dohi, T. Ikura, and K. Igarashi, "Bachl-mediated suppression of p53 is inhibited by p19 ARF independently of MDM2," Cancer Science, vol. 103, no. 5, pp. 897-903, 2012.

[39] A. Nakanome, A. Brydun, M. Matsumoto et al., "Bach1 is critical for the transformation of mouse embryonic fibroblasts by RasV12 and maintains ERK signaling," Oncogene, vol. 32, no. 27, pp. 3231-3245, 2013.

[40] A. Jozkowicz, H. Was, and J. Dulak, "Heme oxygenase-1 in tumors: is it a false friend?" Antioxidants and Redox Signaling, vol. 9, no. 12, pp. 2099-2117, 2007.

[41] P. O. Berberat, Z. Dambrauskas, A. Gulbinas et al., "Inhibition of heme oxygenase-1 increases responsiveness of pancreatic cancer cells to anticancer treatment," Clinical Cancer Research, vol. 11, no. 10, pp. 3790-3798, 2005.

[42] K. Doi, T. Akaike, S. Fujii et al., "Induction of haem oxygenase1 by nitric oxide and ischaemia in experimental solid tumours and implications for tumour growth," British Journal of Cancer, vol. 80, no. 12, pp. 1945-1954, 1999.

[43] M. D. Maines and P.-A. Abrahamsson, "Expression of heme oxygenase-1 (HSP32) in human prostate: normal, hyperplastic, and tumor tissue distribution," Urology, vol. 47, no. 5, pp. 727$733,1996$.

[44] Z.-M. Du, L.-F. Hu, H.-Y. Wang et al., "Upregulation of miR155 in nasopharyngeal carcinoma is partly driven by LMP1 and LMP2A and downregulates a negative prognostic marker JMJD1A," PLoS ONE, vol. 6, no. 4, Article ID e19137, 2011.

[45] A. Harusato, Y. Naito, T. Takagi et al., "Suppression of indomethacin-induced apoptosis in the small intestine due to Bach1 deficiency," Free Radical Research, vol. 45, no. 6, pp. 717727, 2011.

[46] T. Kuroishi, Y. Endo, K. Muramoto, and S. Sugawara, "Biotin deficiency up-regulates TNF- $\alpha$ production in murine macrophages," Journal of Leukocyte Biology, vol. 83, no. 4, pp. 912-920, 2008.

[47] L. Leick, J. F. P. Wojtaszewski, S. T. Johansen et al., "PGC-1 $\alpha$ is not mandatory for exercise- and training-induced adaptive gene responses in mouse skeletal muscle," American Journal of Physiology. Endocrinology and Metabolism, vol. 294, no. 2, pp. E463-E474, 2008.

[48] D. J. Rossi, D. Bryder, J. Seita, A. Nussenzweig, J. Hoeijmakers, and I. L. Weissman, "Deficiencies in DNA damage repair limit the function of haematopoietic stem cells with age," Nature, vol. 447, no. 7145, pp. 725-729, 2007.

[49] K. Naka, T. Muraguchi, T. Hoshii, and A. Hirao, "Regulation of reactive oxygen species and genomic stability in hematopoietic stem cells," Antioxidants and Redox Signaling, vol. 10, no. 11, pp. 1883-1894, 2008.

[50] C. Frezza, L. Zheng, O. Folger et al., "Haem oxygenase is synthetically lethal with the tumour suppressor fumarate hydratase," Nature, vol. 477, no. 7363, pp. 225-228, 2011. 
[51] L. A. Donehower, M. Harvey, B. L. Slagle et al., "Mice deficient for p53 are developmentally normal but susceptible to spontaneous tumours," Nature, vol. 356, no. 6366, pp. 215-221, 1992.

[52] T. Jacks, L. Remington, B. O. Williams et al., "Tumor spectrum analysis in p53-mutant mice," Current Biology, vol. 4, no. 1, pp. 1-7, 1994.

[53] H. Was, M. Sokolowska, A. Sierpniowska et al., "Effects of heme oxygenase-1 on induction and development of chemically induced squamous cell carcinoma in mice," Free Radical Biology and Medicine, vol. 51, no. 9, pp. 1717-1726, 2011.

[54] S. Hira, T. Tomita, T. Matsui, K. Igarashi, and M. Ikeda-Saito, "Bachl, a heme-dependent transcription factor, reveals presence of multiple heme binding sites with distinct coordination structure," IUBMB Life, vol. 59, no. 8-9, pp. 542-551, 2007.

[55] J. S. Lee, W. O. Ward, H. Ren et al., "Meta-analysis of gene expression in the mouse liver reveals biomarkers associated with inflammation increased early during aging," Mechanisms of Ageing and Development, vol. 133, no. 7, pp. 467-478, 2012.

[56] J. R. Paterniti Jr., C. I. P. Lin, and D. S. Beattie, " $\delta$-Aminolevulinic acid synthetase: regulation of activity in various tissues of the aging rat," Archives of Biochemistry and Biophysics, vol. 191, no. 2, pp. 792-797, 1978. 


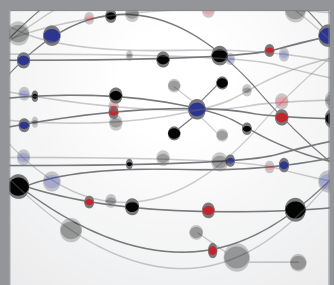

The Scientific World Journal
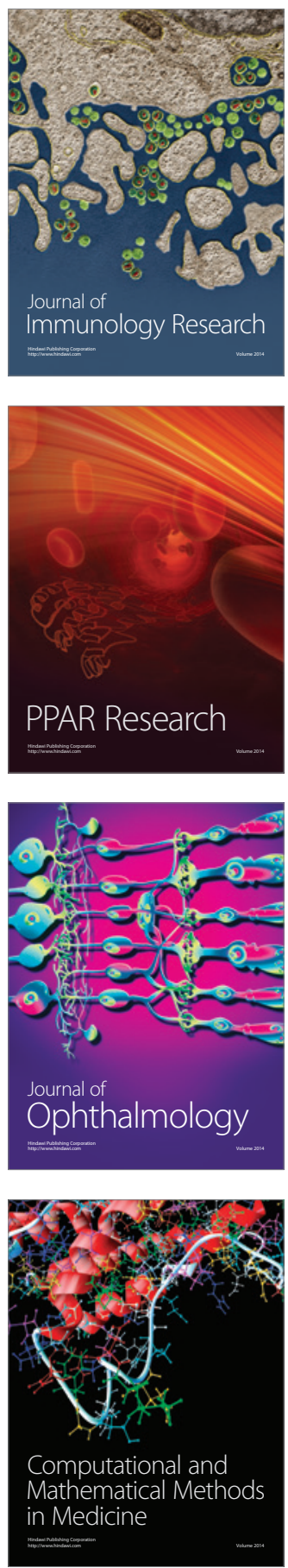

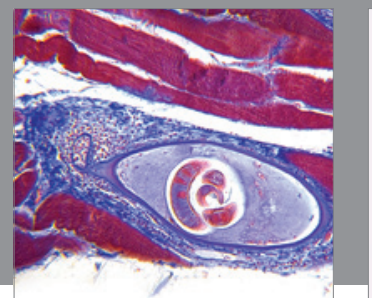

Gastroenterology

Research and Practice
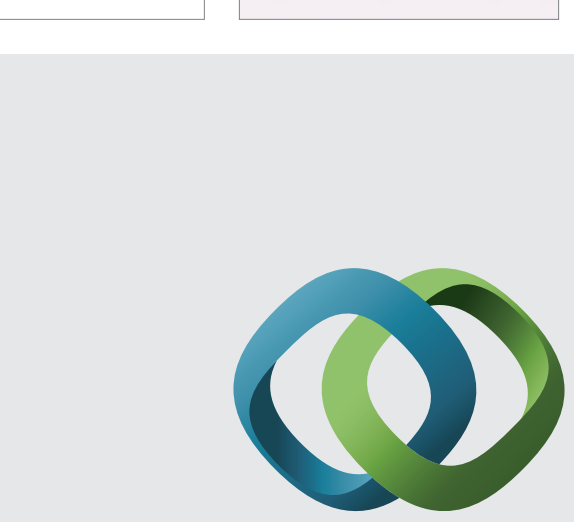

\section{Hindawi}

Submit your manuscripts at

http://www.hindawi.com
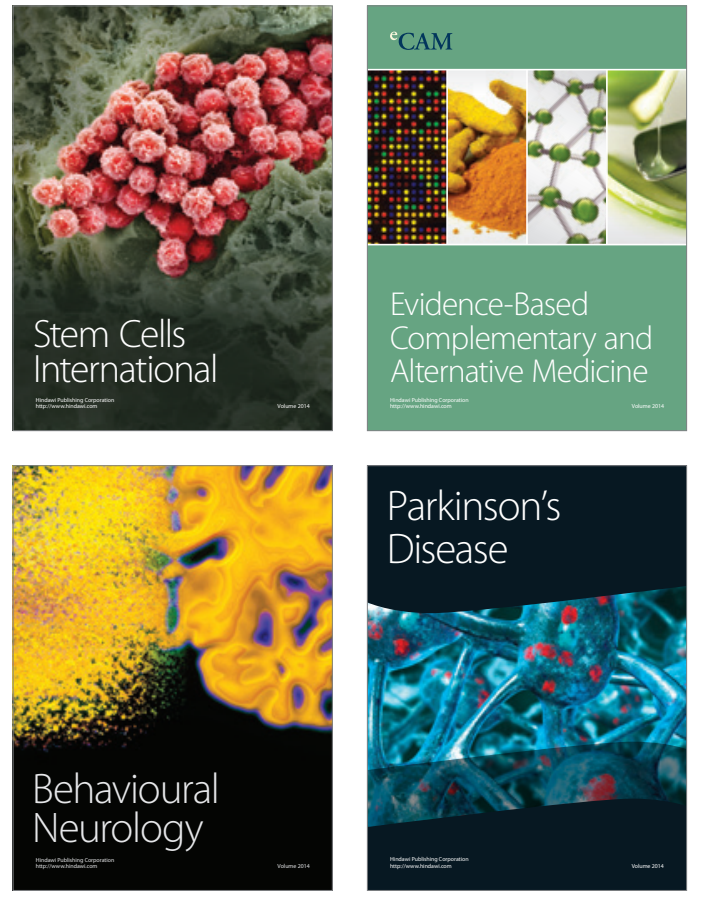
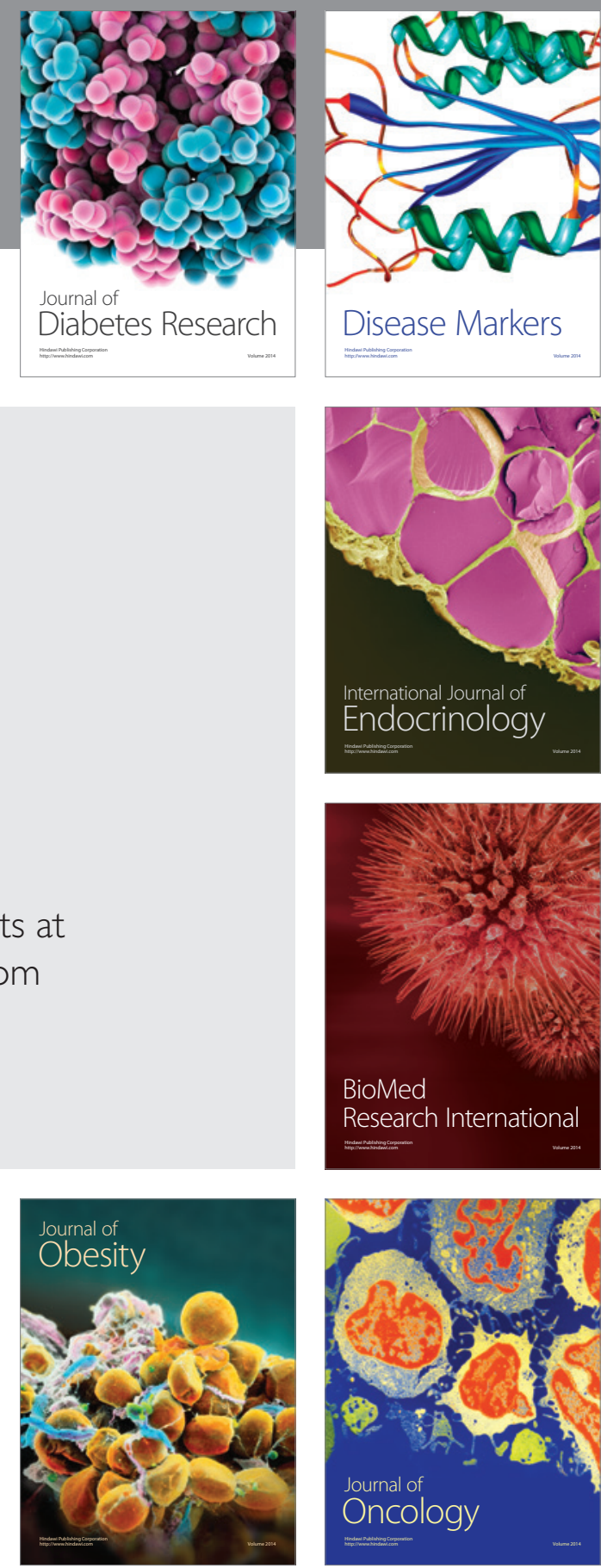

Disease Markers
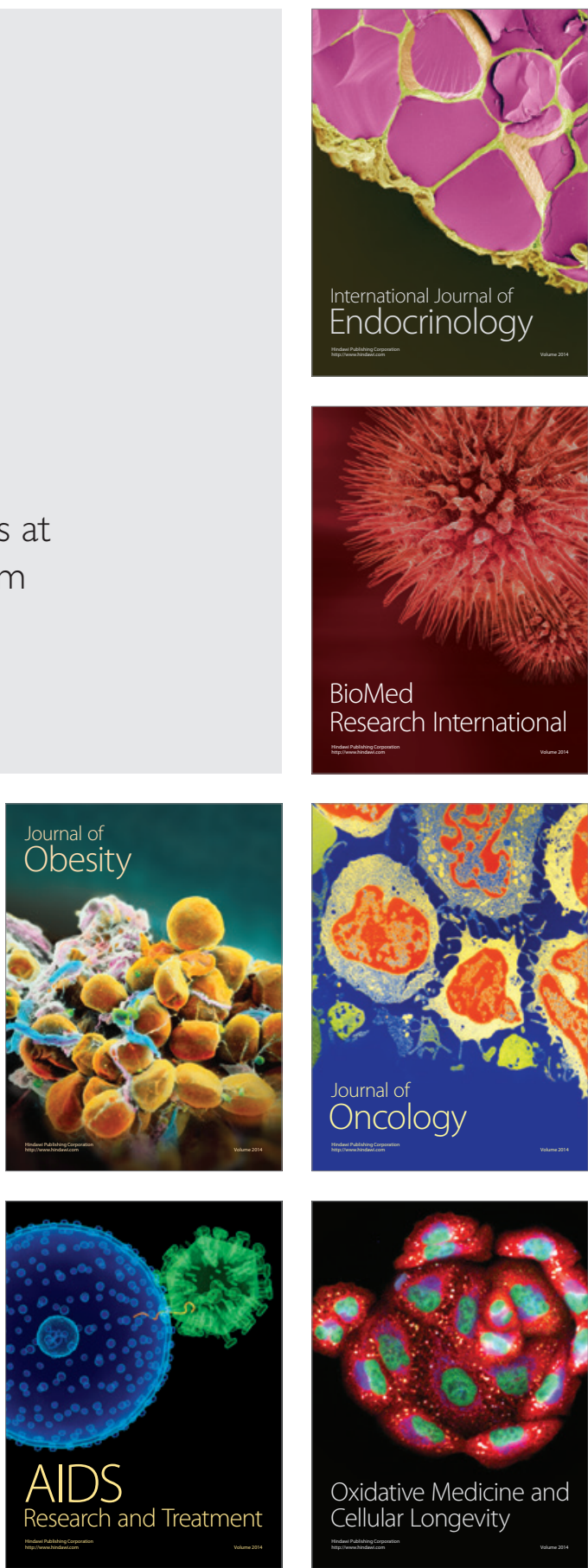